\title{
RANDOM FIELDS OF INITIAL OUT OF STRAIGHTNESS LEADING TO COLUMN BUCKLING
}

\author{
Zdeněk KALA ${ }^{\mathrm{a}}$, Jan VALEŠa ${ }^{\mathrm{a}}$, Jeppe JÖNSSON ${ }^{\mathrm{b}}$ \\ ${ }^{a}$ Department of Structural Mechanics, Faculty of Civil Engineering, Brno University of Technology, \\ Veverí Street 95, 602 00, Brno, Czech Republic \\ ${ }^{b}$ Technical University of Denmark, DTU Civil Engineering, Brovej Building 118, \\ DK-2800 Kongens Lyngby, Denmark
}

Received 26 Apr 2017; accepted 11 May 2017

\begin{abstract}
The elastic load-carrying capacity and buckling trajectory of steel columns under compression with open and hollow cross-sections, whose axis is curved by spatial random fields, are studied in the article. As a result of the spatial curvature of the axis the cross-sections are subjected to compression, bending and torsion from the onset of loading. Numerical simulations are performed using the geometrically non-linear model created using the ANSYS software package. Each simulation run has input random realizations of yield strength and the random field generated using the Latin Hypercube Sampling method. In the plane perpendicular to a perfectly straight column axis, the random observations of deformation trajectories of a node in the middle of the column height are studied. The increasing compression load moves the node along the curve path (open sections) or along the linear path (hollow sections). Large discrepancies in the deformation trajectories of open sections (curvilinear paths) and hollow sections (linear paths) were observed from the comparison of simulation runs. The average and design load-carrying capacities of compressed columns with open cross-sections are lower in comparison to columns with hollow cross-sections due to the lower efficiency of open crosssections in torsion.
\end{abstract}

Keywords: steel structure, imperfections, column, stability, torsional buckling, torsional-flexural buckling, random field, reliability.

\section{Introduction}

The rectangular hollow structural steel section was developed by Stewarts and Lloyds (Wardenier 2002) in 1952. This section, which has almost identical properties as the circular hollow section, enables connections with straight end cuttings. Bridges present a typical example where hollow sections are used extensively for structural applications (Wardenier 2002). These sections have been used for footbridges for over 50 years. Rectangular hollow structural steel sections, as a result of their excellent mechanical properties and geometric tolerances, are frequently used for the construction of high load-bearing structures and numerous researches have been performed on them (King, Davison 2017). Design of hollow sections is due to their special features and connections of more importance than the design of open steel sections (Wardenier 2002). Therefore, designers should pay attention to the different aspects of hollow sections and their effects on structural performance.

For structural components such as columns, which have only a load bearing function, the relevant performance criterion is stability (Rondal et al. 1992; Galambos
1998). The classical solution of Euler's critical load based on one-dimensional (1-D) models of perfectly straight columns can be found in textbooks (e.g. Timoshenko, Gere 1961; Galambos 1998). The calculation of Euler's critical load is useful for normative assessment of reliability of steel elements, for e.g. accoding to Eurocode 3 (EN 1993-1:2005), however, it is hardly applicable for a detailed study of the deformation and stress states of real steel columns with spatial initial imperfections, whose load-carrying capacity is lower than in the case of ideal members.

It should be taken into account that columns with open cross-sections could have resistance to torsionalflexural buckling lower than its resistance to flexural buckling. On the contrary, columns with hollow crosssections have resistance to torsional-flexural buckling usually higher than its resistance to flexural buckling. The effect of random spatial imperfections on the structural performance of a column under compression, which in the case of open cross-sections is more or less reduced due to the effect of torsion, is analysed in the present

Corresponding author: Zdeněk Kala

E-mail:kala.z@fce.vutbr.cz 
article. Open cross-sections of imperfect columns do not resist torsion as effectively as hollow cross-sections, which affects their limit states. The limit states are analysed using the geometrically non-linear solution based on advanced beam finite elements BEAM188 (ANSYS 2014) that include new warping degrees of freedom, which are very effective for advanced modelling of twisted beams (Murín, Kutiš 2008; Murín et al. 2014, 2017).

Finite elements used for the analysis of steel beam structures are based in most engineering applications on the classic Euler-Bernoulli beam theory, which assumes that the plane cross-sections remain plane and normal to the neutral axis before bending and plane cross-sections remain plane and normal to the neutral axis after bending. A more detailed description is presented by Timoshenko beam theory (Timoshenko 1934), which assumes that the cross-sections remain plane and undistorted after deformation, but permits rotation between the cross-section and the bending line. This rotation comes from a shear deformation, which is not included in a Bernoulli beam.

The Timoshenko beam theory is a so-called first order shear deformation theory, where transverse shear strain is constant through the cross-section, thus the effect of shear deformation on the cross-section is captured in an average sense (Groh, Weaver 2015). Two-dimensional extension of this theory for isotropic and single-layer plates was presented by Mindlin (1951) and extended to multi-layered plates by Yang et al. (1966). Other theories, which are generally referred to as higher-order shear deformation theories, have been developed by other researchers (Levinson 1981; Fatmi 2007). A comprehensive higher order beam formulation was presented by Argyris and Kačianauskas (1996). However, increased efforts have not lead to higher accuracy, therefore the first order shear deformation theory remains in practical use (Senjanović et al. 2016). Generally, the limit states of steel structures can be studied using 3D models based on shell (Ádány 2014; Jönsson, Stand 2017) or solid (Králik 2009; Kala, Valeš 2017) finite elements. However, for computational efficiency, beam theory and elements (involving much less degrees of freedom) are normally favoured without compromising the computational accuracy (see e.g. Kala 2012, 2016b).

The load-carrying capacity of columns under compression with intermediate slenderness (non-dimensional slenderness around 0.9 ) is very sensitive to the initial geometric imperfection of the initial out-of-straightness of the column. This was proven by sensitivity analyses of planar buckling (Kala 2009, 2016b). Common models are based on an approximation of the initial out-ofstraightness using a half-wave sinusoidal function for compressed columns (Kala 2009) or a scaling of the first eigenvalue buckling mode shape for frame structures (Kala 2016b). An advantage of these models is that the curvature of the axis of the loaded column is affine to the initial out-of-straightness. Based on these assumptions it is not difficult to analyse the limit states of columns and in many cases solutions are available in the closed form (Trahair 1977). The outputs of analytical models are clearly influenced by the amplitude of the initial out-of-straightness, used by design standards (EN 1993-1:2005), which introduce the so-called equivalent geometrical imperfection covering not only geometric, but also structural imperfections (Agüero, Pallarés 2015; Pasternak, Kubieniec 2016). However, the Eurocode equivalent of geometrical imperfections may be very conservative as was shown by study of Jönsson and Stand (2017). In stochastic models the amplitude of the initial out-of-straightness of a beam is usually introduced as a purely geometrical imperfection without correlation with other imperfections, which are modelled separately (Kala, Valeš 2017). In some stochastic models, initial geometrical imperfections are introduced as a linear superposition of several scaled buckling modes, where the scale factor and random sign of each mode are random variables (Shayan et al. 2014; Zhang et al. 2016).

The random shape of the axis of a real column can be modelled using a higher number of mutually correlated random variables (Kala 2007). One of the widespread modelling approaches of spatial correlation in engineering applications is based on random fields (Matthies et al. 1997; Matthies, Bucher 1999). Fundamentals of the analysis of random fields are described in Vanmarcke (1983). Random fields describe the random variability of most structural material and geometrical properties very precisely (Bucher 2006; Vryzidis et al. 2013; Chen et al. 2016). Taking into account random fields is crucial in the accurate prediction of system performances, especially field-sensitive failures like buckling (Xi 2015). Sensitivity of the load-carrying capacity to the shape and size of spatial axial curvature of the column increases significantly if the second moment of area of the column crosssection is the same for all rotations of orthogonal coordinate axes passing through the centre of gravity (principal second moments of area are the same). Hollow structural sections of circular or square shape have this property. Spatial axial curvature of a column under compression results in torsion of the cross-sections in addition to compression and bending.

The subject of this article is the stochastic analysis of the elastic load-carrying capacity (further denoted as LCC) of a column under compression, which is hinged at both ends. LCC is defined as the maximum load at which the yield strength is reached in the most stressed area of the column. The shape of the initial out-of-straightness of the column is modelled using random fields, which are generated using the Latin Hypercube Sampling (LHS) method (McKey et al. 1979; Iman, Conover 1980). The column is modelled using the finite element BEAM188, which can also take into account warping (non-uniform) torsion (Vlasov 1959). As was corroborated by recent studies (Rubin 2006; Murín, Kutiš 2008; Murín et al. 2014, 2017; Mokos, Sapountzakis 2011) the effect of non-uniform torsion should be considered not only for 
(a)

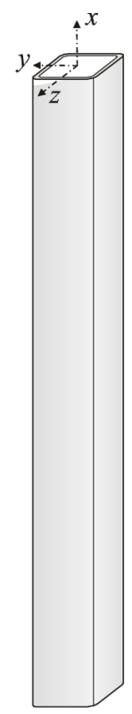

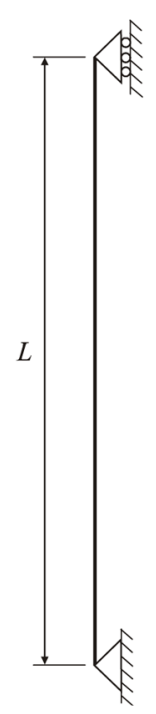

(b)

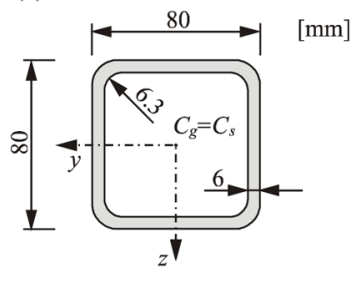

(c)

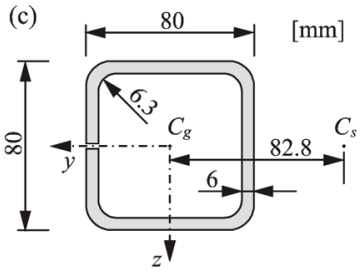

Fig. 1. Column with square cross-sections

beams with open cross-sections, but also for beams with hollow cross-sections. For columns under compression with spatial (in shape and size) random initial out-ofstraightness the load-deflection characteristics are given as loading combinations of compression, bending and torsion. Random deformations and LCC of spatial imperfect columns with hollow (torsionally rigid) and open (torsionally soft) square cross-sections are analysed in this article.

\section{Stochastic finite element model}

The static resistance of a column under compression is analysed using beam finite elements, denoted as BEAM188 element in (ANSYS 2014). The BEAM188 is based on Timoshenko beam theory. The BEAM188 element is suitable for large strain nonlinear analysing of slender to moderately thick beam structures. BEAM188 is a 2-node beam element in 3-D, which has seven degrees of freedom at each nodal point. The degrees of freedom contain three translations along axes $x, y, z$, three rotations around these axes and furthermore warping degree of freedom, which represents the warping part of the first derivative of the angle of twist, resulting from the bimoment. Consideration of warping degree of freedom permits its use for the satisfaction of boundary conditions e.g. at clamped ends of beams (Murín et al. 2017). Inclusion of the warping degree of freedom further provides the finite element the capability to analyse the influence of bimoment and warping torsion on the stress state of beam structures.

A steel column of length $L=2.798$ m was analysed. The length of the column is chosen so that the non-dimensional slenderness of the planar strut acc. to (EN 1993-1:2005) is equal to one, and thus high sensitivity of LCC to the initial out-of-straightness can be expected (Kala 2009, 2016b).

\subsection{Boundary conditions and cross-section variants}

The boundary conditions of the column are depicted in Figure 1. The bottom node has null translations along all three axes and null rotation around axis $x$. The top node has null translations along axes $y$ and $z$ and null rotation around axis $x$. Both end cross-sections have null warping (axial) displacements. The model is subjected to vertical compressive load at the top node $b$ in the direction of a line passing through nodes $a$ and $b$. The value of the reaction along the $x$-axis is monitored at node $a$ for the determination of LCC.

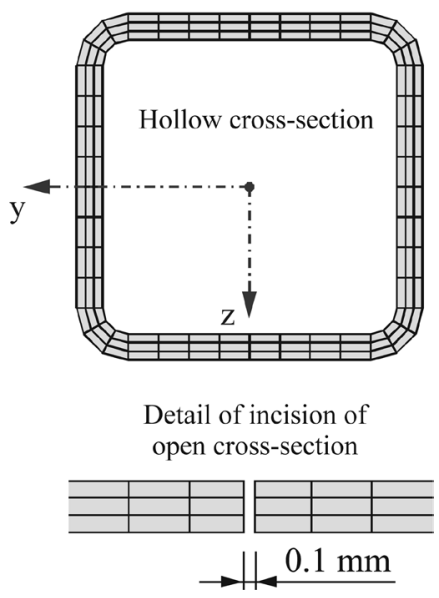

Fig. 2. Cross mesh of finite element BEAM188

Since the size of the incision is very small $(0.1 \mathrm{~mm})$ and the incision is not displayed during the meshing of the cross-section, the mesh of element BEAM188 is displayed identically for both hollow and open sections. Therefore, the mesh shown in Figure 2 applies to the hollow section and all cases of incision positions depicted in Figure 4. The detail of the part of the cross-section with incision is depicted in Figure 2. The example of the stress state, if hollow cross-section, in Figure 3 is depicted for the most stressed part of the column, whose initial geometrical imperfections are depicted in Figure 5. The most stressed part is located at approximately two-fifths of the height of the column, see Figure 6.

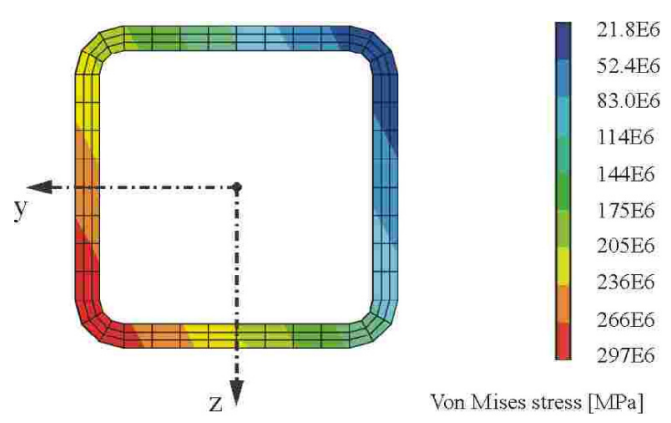

Fig. 3. Example of the von Mises stress state of BEAM188 

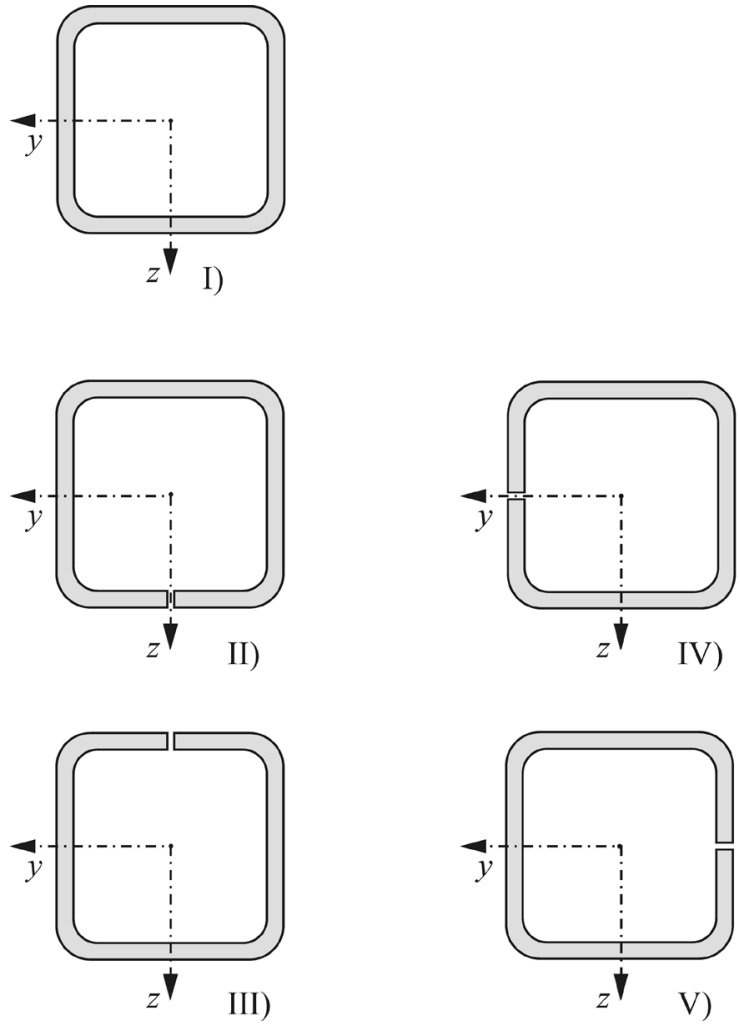

Fig. 4. Variants of square cross-section

The cross-section characteristics are listed in Table 1, where $A$ denotes the area, $I_{y}$ is second moment of area about axis $y, I_{z}$ is second moment of area about axis $z, I_{\omega}$ is warping constant, $I_{t}$ is torsion constant, $E$ is Young's modulus of elasticity, $G$ is shear modulus. It is apparent that the difference between a section without an incision and a section with an incision only affects characteristics $I_{\omega}$ and $I_{t}$, associated with torsion. This means that differences in the behaviour of the beam during loading and when it reaches the limit state are due to torsion. Let us remark that the cross-section with such a small incision is only theoretical and it is used just to highlight advantages of a hollow cross-section, especially its much higher torsional stiffness.

Table 1. Cross-section characteristics

\begin{tabular}{c|l|l}
\hline Characteristics & \multicolumn{1}{|c}{ Hollow } & \multicolumn{1}{|c}{ Open } \\
\hline$A$ & $1.683 \mathrm{E}-3 \mathrm{~m}^{2}$ & $1.683 \mathrm{E}-3 \mathrm{~m}^{2}$ \\
$I_{y}$ & $1.492 \mathrm{E}-6 \mathrm{~m}^{4}$ & $1.492 \mathrm{E}-6 \mathrm{~m}^{4}$ \\
$I_{z}$ & $1.492 \mathrm{E}-6 \mathrm{~m}^{4}$ & $1.492 \mathrm{E}-6 \mathrm{~m}^{4}$ \\
$I_{\mathrm{W}}$ & $2.827 \mathrm{E}-12 \mathrm{~m}^{6}$ & $6.115 \mathrm{E}-9$ \\
$I_{t}$ & $2.529 \mathrm{E}-6 \mathrm{~m}^{4}$ & $1.997 \mathrm{E}-8$ \\
$E$ & $210 \mathrm{GPa}$ & $210 \mathrm{GPa}$ \\
$G$ & $81 \mathrm{GPa}$ & $81 \mathrm{GPa}$ \\
\hline
\end{tabular}

\subsection{Eigenvalue buckling analysis}

The eigenvalue buckling analysis predicts the theoretical buckling (critical) load of an ideal elastic column. Table 2 lists the first three eigenvalues for hollow and open cross-sections.
Table 2. The first three eigenvalues

\begin{tabular}{c|c|c}
\hline Eigenvalue & Hollow & Open \\
\hline $1^{\text {st }}$ & $392.4 \mathrm{kN}$ & $201.0 \mathrm{kN}$ \\
$2^{\text {nd }}$ & $392.4 \mathrm{kN}$ & $392.0 \mathrm{kN}$ \\
$3^{\text {rd }}$ & $1540.1 \mathrm{kN}$ & $396.6 \mathrm{kN}$ \\
\hline
\end{tabular}

The first two eigenvalues of the column are the same for the hollow cross-section, because the principal second moments of area of the square cross-section are the same. Non-dimensional slenderness calculated from the $1^{\text {st }}$ eigenvalue $392.4 \mathrm{kN}$ acc. to EN 1993-1:2005 is equal to 1.0. The first and second buckling mode shape is half a sine wave, the third buckling mode shape is a sine wave.

In the case of the open cross-section, the first and second buckling mode shape is half a sine wave in the plane, however, torsion occurs in the first mode shape. The non-dimensional slenderness calculated from the $1^{\text {st }}$ eigenvalue $201.0 \mathrm{kN}$ is 1.4 . Torsion does not occur in the second shape and the eigenvalue is very close to the value of the hollow cross-section.

Eigenvalue buckling analysis shows the most important differences between columns with open and hollow cross-sections. In reality, however, due to structural imperfections and non-linearities most real-world structures do not attain their eigenvalue predicted buckling strength.

\subsection{Random field model}

The initial spatial out-of-straightness of the column is modelled using eleven nodes, which is fitted with a spline, see example in Figure 5. The distance between adjacent nodes of the spline along axis $x$ is $x_{i+1}-x_{i}=$ $0.2798 \mathrm{~m}$. While the $x$ coordinates of the nodes are fixed, $y$ and $z$ coordinates are random variables with a Gauss probability density function (pdf) with null mean value and standard deviation given by the relation:

$$
S_{i}=S_{a} \sin \left(\frac{\pi x_{i}}{L}\right)
$$

where $x_{i}$ is the position on the beam axis and $S_{a}$ is the amplitude calculated on the assumption that $95 \%$ of the random realizations of the maximal initial spatial deformation are within the tolerance limit of (Kala 2011; Kala, Z., Kala, J. 2011). The coordinate values in each of the two planes are mutually correlated through the Gaussian correlation function (2), which represents a 1D random field with correlation length $L_{c o r}=1.44165 \mathrm{~m}$ (Valeš 2013).

$$
\rho_{j h}=e^{-\left(\xi_{j h} / L_{c o r}\right)^{2}},
$$

where $\xi_{j h}$ is the distance between two points measured along axis $x$. The correlation length $L_{c o r}$ is a parameter, which influences the random shape of the initial out-ofstraightness of the column. If $L_{c o r} \rightarrow \infty$, then $\rho_{j h} \rightarrow 1$ and the shape of the initial out-of-straightness converges to a half-wave of the sinusoidal function. If $L_{c o r}=0$, then $\rho_{j h}=0$ and the $y$ and $z$ coordinates of nine nodes are sta- 
tistically independent, which is unrealistic. It may be noted that the use of linear or exponential correlation functions may also be discussed (Chen et al. 2016), however, it would require that the correlation length of $1.44165 \mathrm{~m}$ used here is introduced with a higher value.

The Gaussian correlation function (2) models a correlation whose decay rate increases with distance. Correlation is only considered between the coordinate values of nodes in one plane, i.e., the initial out-of straightness in one plane is independent to the initial out-of straightness in another plane. Correlation matrix (3) consists of four submatrices, where the submatrix with non-zero elements describes the correlation between nodes in one plane and the submatrix with zero elements describes the correlation between nodes in both planes. The dimension of correlation matrix (3) is $18 \times 18$, because the initial deformation of the first and last node is equal to zero. Each non-zero element in Eqn (3) is calculated using Eqn (2).

The random field based on Eqns (1) and (3) is nonhomogeneous, because the variances of the geometric imperfections at different nodes are not the same. Detailed information about the random field theory can be found in a number of books like (Vanmarcke 2010; Adler, Taylor 2007).

$$
[K]=\left[\begin{array}{cc}
K_{1} & 0 \\
0 & K_{1}
\end{array}\right]
$$

where

$$
\left[K_{1}\right]=\left[\begin{array}{ccccccccc}
1 & 0.963 & 0.860 & 0.712 & 0.547 & 0.390 & 0.258 & 0.158 & 0.090 \\
0.963 & 1 & 0.963 & 0.860 & 0.712 & 0.547 & 0.390 & 0.258 & 0.158 \\
0.860 & 0.963 & 1 & 0.963 & 0.860 & 0.712 & 0.547 & 0.390 & 0.258 \\
0.712 & 0.860 & 0.963 & 1 & 0.963 & 0.860 & 0.712 & 0.547 & 0.390 \\
0.547 & 0.712 & 0.860 & 0.963 & 1 & 0.963 & 0.860 & 0.712 & 0.547 \\
0.390 & 0.547 & 0.712 & 0.860 & 0.963 & 1 & 0.963 & 0.860 & 0.712 \\
0.258 & 0.390 & 0.547 & 0.712 & 0.860 & 0.963 & 1 & 0.963 & 0.860 \\
0.158 & 0.258 & 0.390 & 0.547 & 0.712 & 0.860 & 0.963 & 1 & 0.963 \\
0.090 & 0.158 & 0.258 & 0.390 & 0.547 & 0.712 & 0.860 & 0.963 & 1
\end{array}\right]
$$

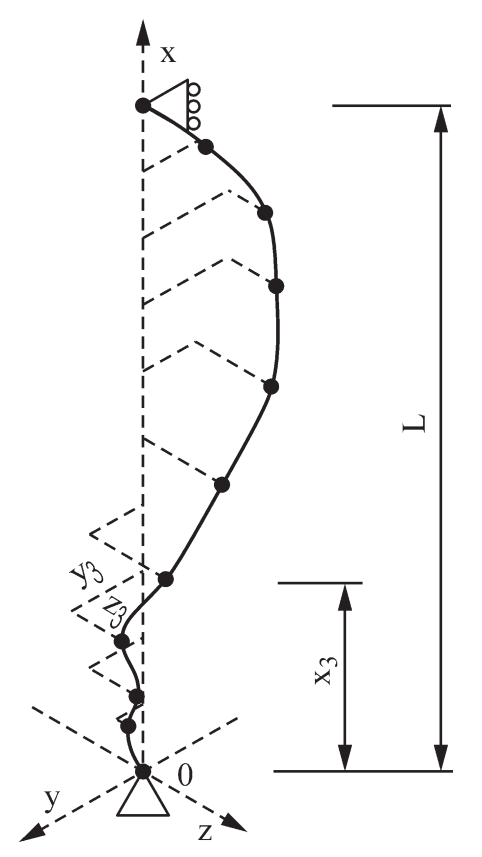

Fig. 5. Example of spatial depiction of the imperfection

Another random input variable is the yield strength. The yield strength $f_{y}$ is considered with Gauss pdf with mean value of $297.3 \mathrm{MPa}$ and standard deviation $16.8 \mathrm{MPa}$ (Melcher et al. 2004). These statistical characteristics of yield strength were obtained from experimental research and are frequently used in a number of reliability studies (see for e.g. Chen et al. 2016; Thai et al. 2016). In total the stochastic finite element model has 19 input random variables.

\section{Load-carrying capacity}

The LCC is the studied output random variable. Numerical simulations are performed as a process of running a geometrically non-linear model with regard to initial geometric imperfections and yield strength. Random realizations (hereinafter referred to as realizations) of yield strength and initial out-of-straightness of the column are simulated using the LHS method (McKey et al. 1979; Iman, Conover 1980), which is part of the software Freet (Vořechovský, Novák 2009). The so-called setting "mean" (Huntington, Lyrintzis 1998) is used. 62 realizations are generated for 19 input random variables. LCC is calculated successively for all variations of the position of the incision in Figure 4, which means that a total of 62 runs in five series are evaluated.

The LCC is calculated with an accuracy of $0.1 \%$ in each simulation run. Load-deflection characteristics are calculated using the step by step method. The column is loaded incrementally with axial load $N$ and a constant 


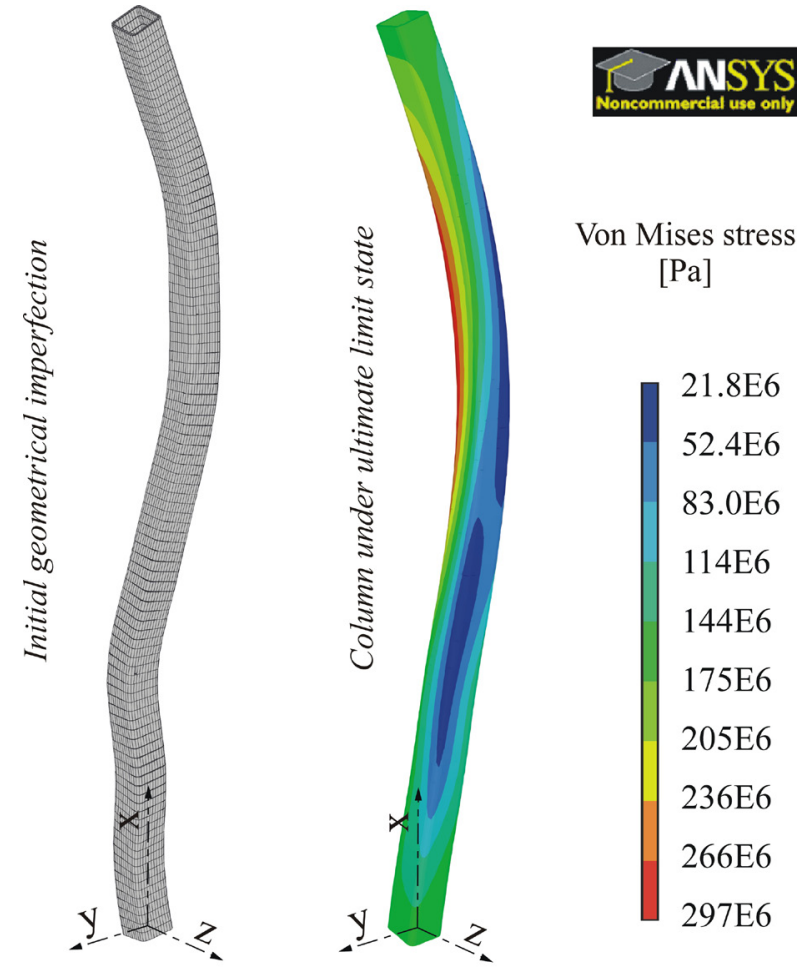

Fig. 6. Finite element analysis of column with hollow crosssection

number of increments $n_{\text {step }}$. The size of load $N$ is chosen so that its effect results in the stress exceeding the yield strength of steel $f_{y}$ anywhere in the beam. For this to occur, the elastic stress-strain material relationship is used. The value of LCC is then calculated using linear interpolation of the stress $\sigma_{N}$ from the step at which the yield strength is exceeded $n_{N}$ and stress $\sigma_{N-1}$ from the preceding step $n_{N-1}$ as:

$$
L C C=\frac{N}{n_{\text {step }}}\left[n_{N-1}+\left(f_{y}-\sigma_{N-1}\right) \frac{n_{N}-n_{N-1}}{\sigma_{N}-\sigma_{N-1}}\right] .
$$

Figure 6 shows a comparison of the unloaded column with initial geometrical imperfection with the deformed column under ultimate limit state. The initial imperfection in Figure 6 is the same as the initial imperfection in Figure 5.

Upon reaching the LCC the stress of the column with hollow cross-section and cross-section with an incision is more or less different. The different stress distribution of the column with hollow and open cross-section is clearly visible, for e.g. in the first simulation, see Figure 7. Torsion has an influence on both the deformation and the stress in the column at limit state.

\section{Deflection curves analysis}

Deflection curves of columns under compression are shown in Figure 8. All the curves are plotted for the sixth node, which is located halfway up the column. Five deflection curves, which show the growth of the deforma-

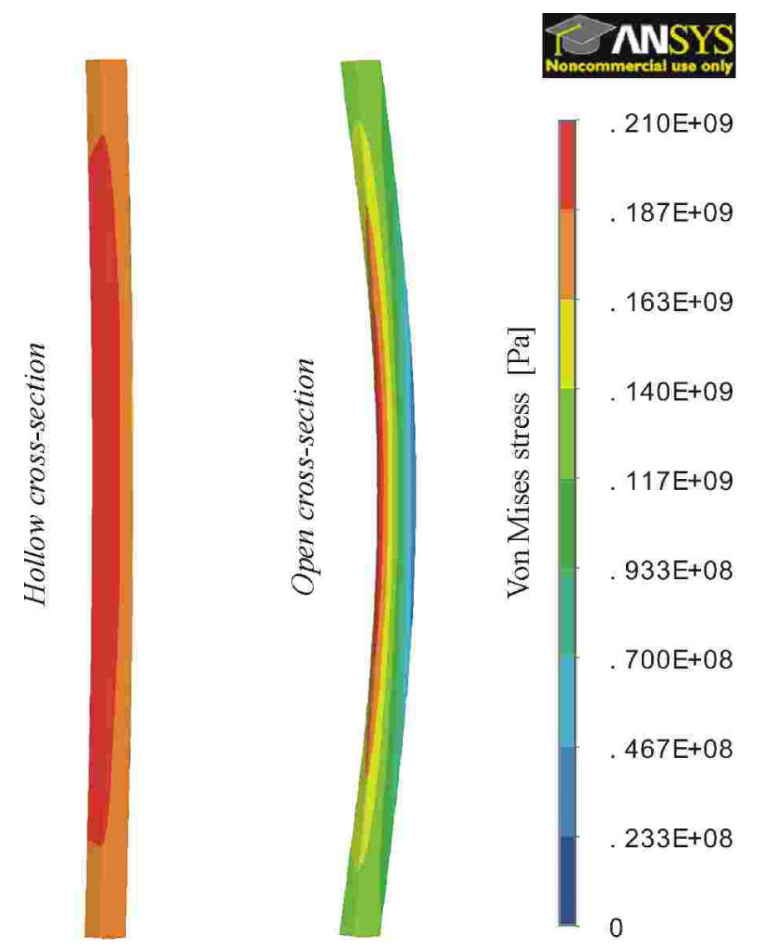

Fig. 7. Comparision of von Mises stress of two columns at ultimate limit state

tion in the process of loading the column, emanate from the point of the initial imperfection. The point of the initial imperfection has a random position and corresponds to zero stress at the beginning of loading. The five deflection curves displayed for 62 realizations describe the behaviour of the column with hollow section (solid red line) and four variants of the open section (four dashed lines), see Figure 8. Although the curves emanate from one point, each ends at a different point. The end of the curve represents the point at which the yield strength is reached in the most stressed area of the column and the load terminates upon reaching LCC.

The following observations can be drawn from the curves depicted in Figure 8. The deformation of the column with cross-section I (hollow) is linear for each realization of the initial axial out-of-straightness. Deformations pertinent to open cross-sections have a more or less curved trajectory. The difference between trajectories of the deformations of cross-sections II and III are very small; see the red and green dashed lines in Figure 8. A typical example is realization $\mathrm{R} 14$. The red and green trajectories II and III slightly diverge each in the direction of the location of the incision. The trajectories of the deformations of cross-sections IV and V are very similar; see purple and blue dashed lines. Trajectories IV and V slightly diverge, each following the direction of its incision. It is important to remind that a beam finite element was used. Therefore, the cross-section remains rigid during loading, regardless of cross-section type. 

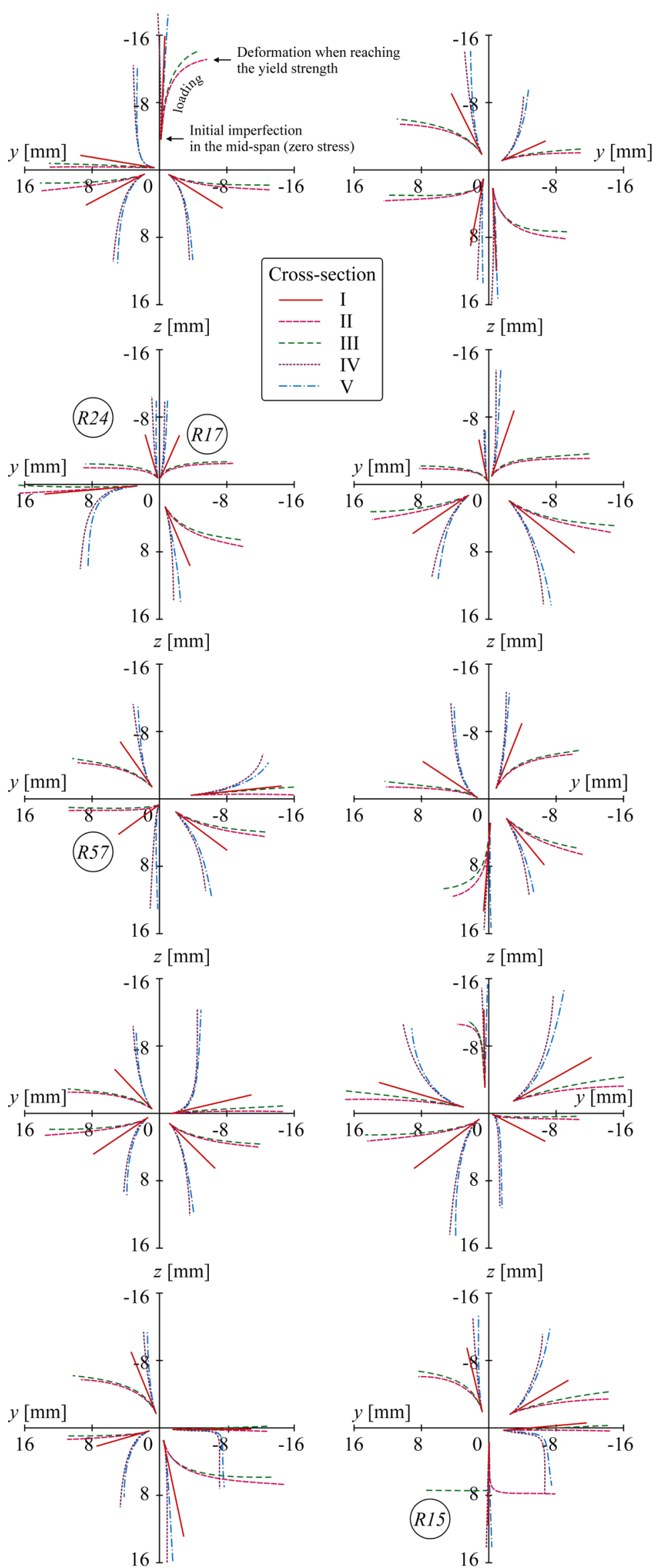

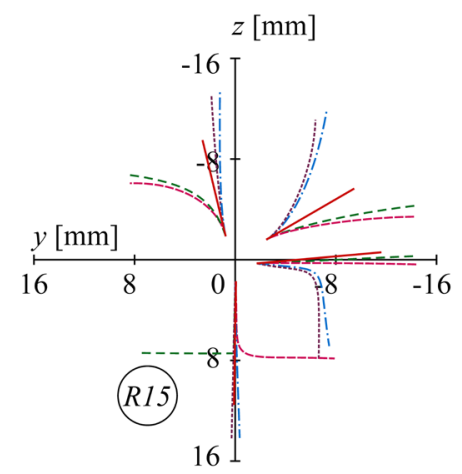

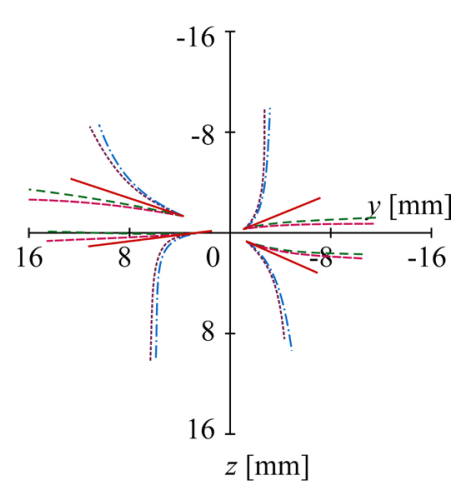
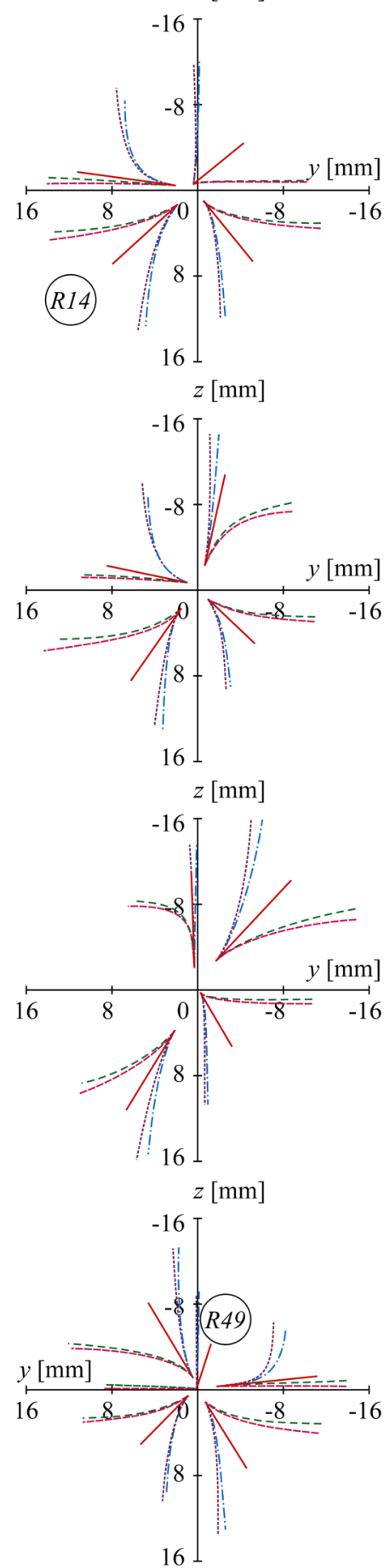

Fig. 8. Deflection curves of columns at the node in $x=L / 2$ 
It can be concluded that the incisions on opposite sides have very similar deformation curves. An exception is in cases of very small values of initial imperfections, see realization R15. Initial imperfection of realization R15 is practically zero along axis $y$. Buckling of the cross-section with an incision on the $z$-axis occurs in the direction of $y$-axis for cross-section III and against the direction of the $y$-axis for cross-section II. Deformation curves of open cross-sections of realization R49, which have practically zero initial imperfection on both axes, are interesting. Deformation trajectory R49 are always perpendicular to the axis on which the incision is located. Very similar observations can be made in realizations R57, R24 and R17. The process of buckling of open cross-sections is thus predetermined by both the shape of initial spatial axial out-of-straightness of the column and the location of the incision on the cross-section. Buckling of open cross-sections always leads to greater deformations upon reaching LCC in comparison with the same realization of hollow cross-sections.

\section{Statistical analysis of LCC}

The results of statistical analysis of LCC of the columns are listed in Table 3. The differences in the statistics pertaining to hollow cross-section I and statistics of other open cross-sections II to $\mathrm{V}$ are evident. Let us denote LCC of the column with cross-section I as $\mathrm{LCC}_{\mathrm{I}}$, of column with cross-section II as $\mathrm{LCC}_{\mathrm{II}}$, etc. The mean value of $\mathrm{LCC}_{\mathrm{I}}$ is $20 \%$ greater than the mean value of the other LCC. The standard deviation of $\mathrm{LCC}_{\mathrm{I}}$ is $40 \%$ greater than the standard deviation of the other LCC. The skewness of $\mathrm{LCC}_{\mathrm{I}}$ is positive while the skewness values of the other LCC are negative. The kurtosis of $\mathrm{LCC}_{\mathrm{I}}$ is greater than three, while the kurtosis of the other LCC are lower than three.

Very strong correlation of 0.97 is observed between $\mathrm{LCC}_{\mathrm{II}}$ and $\mathrm{LCC}_{\mathrm{III}}$ and between $\mathrm{LCC}_{\mathrm{IV}}$ and $\mathrm{LCC}_{\mathrm{V}}$, see Figure 9. Zero correlation is obtained between LCC of columns, whose cross-sections have incisions rotated by 90 degrees. Strong correlation of approximately 0.72 is between $\mathrm{LCC}_{\mathrm{I}}$ and the other LCC.

Table 3. Statistical characteristics of LCC

\begin{tabular}{ccccc}
\hline $\begin{array}{c}\text { Cross- } \\
\text { section }\end{array}$ & $\begin{array}{c}\text { Mean value } \\
{[\mathrm{kN}]}\end{array}$ & $\begin{array}{c}\text { Std. } \\
\text { Deviation } \\
{[\mathrm{kN}]}\end{array}$ & Skewness & Kurtosis \\
\hline I. & 326.18 & 24.735 & 0.121 & 3.194 \\
II. & 271.96 & 16.595 & -0.437 & 2.663 \\
III. & 271.93 & 17.074 & -0.503 & 2.571 \\
IV. & 271.15 & 17.295 & -0.310 & 2.288 \\
V. & 271.11 & 17.187 & -0.360 & 2.602 \\
\hline
\end{tabular}

It should be noted that skewness and kurtosis are functions of higher order statistical moments, which are calculated with higher statistical error than mean value and standard deviation, see Table 3. Each of the cases II to V should theoretically have the same statistical mo-

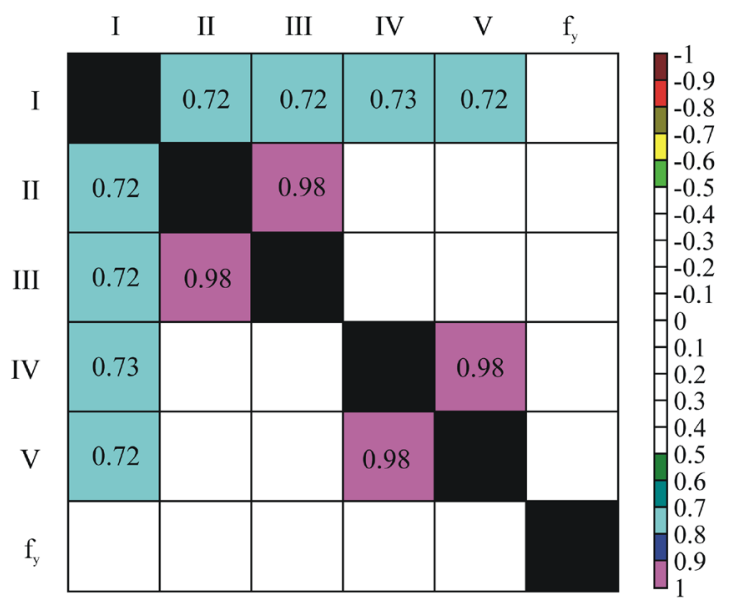

Fig. 9. Correlation among LCC cases and yield strength $f_{y}$

ment, which could be achieved by using a very high number of simulation runs. Application of the evaluated realizations can be used to improve the estimation of statistical moments by calculating the arithmetical mean from II to V. In this manner, we can write the statistical moments of LCC of the column with, generally, open cross-section and random incision position, see Table 4. The results listed in Table 4 transparently compare LCC of the column with hollow and open cross-section.

Table 4. Statistical characteristics of LCC

\begin{tabular}{lccll}
\hline $\begin{array}{c}\text { Cross- } \\
\text { section }\end{array}$ & $\begin{array}{c}\text { Mean value } \\
{[\mathrm{kN}]}\end{array}$ & $\begin{array}{c}\text { Std. } \\
\text { Deviation } \\
{[\mathrm{kN}]}\end{array}$ & Skewness & Kurtosis \\
\hline Hollow & 326.18 & 24.735 & 0.121 & 3.194 \\
Open & 271.54 & 17.038 & -0.403 & 2.531 \\
\hline
\end{tabular}

The category of open cross-sections in Table 4 practically represents a column with spatial axial curvature modelled using the stochastic finite element model described above, in which the position of the incision is generated using a random number from one to four in each simulation run. Practically, the statistical moments in the category of open cross-sections can also be calculated from the set of 248 realizations of LCC, which are all the calculated realizations from categories II, III, IV and $\mathrm{V}$.

The comparison of the random LCC of columns with hollow and open cross-section is clearly shown in Figure 10 after approximation using Gauss and Hermite pdfs in the software Statrel 3.10. Hermite pdf is a four-parameter pdf, which respects not only the arithmetic mean and standard deviation, but also the skewness and kurtosis of valid observations. Methods for introducing the third and fourth parameter of the Hermite pdf are mathematically described and discussed in Kala (2016a). Differences between the Gauss and Hermite pdfs are small in the case of the hollow cross-section, but high in the case of the open cross-section, see Figure 10. 
In order to calculate the design quantiles, we test if the realization of LCC fits Gauss, lognormal or Hermite pdf. LCC realizations are subjected to three probability distribution tests at the critical 5\% significance level. Statistical evaluation is performed using the program Statrel 3.10. Five sets each with 62 realizations of LCC are compared one by one with Gauss, lognormal and Hermite pdfs. The selected goodness of fit tests are: a) Kolmogorov-Smirnov test (Massey 1951); b) Chi-Square test (Pearson 1900); c) Anderson-Darling test (Anderson, Darling 1952, 1954). If the test determines that "the hypothesis should not be rejected", the corresponding symbol a), b), c), is added to the numerical value of the quantile, see Table 5. Otherwise, the data is not from the respective pdf.

Table 5. 0.1 percentiles of LCC (design values)

\begin{tabular}{cccc}
\hline $\begin{array}{c}\text { Cross- } \\
\text { section }\end{array}$ & $\begin{array}{c}\text { Gauss pdf } \\
{[\mathrm{kN}]}\end{array}$ & $\begin{array}{c}\text { Lognormal } \\
\text { pdf } \\
{[\mathrm{kN}]}\end{array}$ & $\begin{array}{c}\text { Hermite pdf } \\
{[\mathrm{kN}]}\end{array}$ \\
\hline I. & $249.74^{\mathrm{abc}}$ & $257.39^{\mathrm{abc}}$ & $246.24^{\mathrm{abc}}$ \\
II. & $220.68^{\mathrm{ac}}$ & $224.85^{\mathrm{ac}}$ & $206.60^{\mathrm{ac}}$ \\
III. & $219.17^{\mathrm{abc}}$ & $223.57^{\mathrm{abc}}$ & $201.19^{\mathrm{abc}}$ \\
IV. & $217.7^{\mathrm{abc}}$ & $222.23^{\mathrm{abc}}$ & - \\
V. & $217.99^{\mathrm{abc}}$ & $222.47^{\mathrm{abc}}$ & $209.57^{\mathrm{ac}}$ \\
\hline
\end{tabular}

Table 5 contains the design values of LCC, which are calculated as 0.1 percentiles according to the European standard EN 1990. Calculation of the 0.1 percentile is based on the semi-probabilistic approach of standard EN 1990 (2003) and represents the basic reliability targets for design values for ultimate limit states recommended in EN 1990 for a reference period of 50 years (Sedlacek, Müller 2006). Comparison of the 0.1 percentile with the design value calculated according to EN 1993-1:2005 is the fundamental approach to statistical verification of the reliability of steel structures (Kala et al. 2009, 2016). If the response of the structure fits the Gauss pdf, the structural reliability can be verified by comparing the calculated reliability index $\beta$ with the target reliability index $\beta_{\mathrm{d}}=3.8$ (see e.g. Sedlacek, Kraus 2007; Vainiūnas et al. 2015; Kamiński, Świta 2015). The target reliability index $\beta_{\mathrm{d}}=3.8$ corresponds to a target failure probability $7.2 \mathrm{E}-5$ and design LCC calculated as 0.1 percentile, see EN1990. In the case that the calculated failure probability is greater than the target value, the structure is considered unsafe (see e.g. Kala 2015). Semi-probabilistic design reliability conditions of standard EN 1990 (2003) permits the evaluation of the 0.1 percentile using Gauss pdf or lognormal pdf, which is usually acceptable in cases where the skewness is close to zero and the kurtosis is close to three.

The statistical analysis of LCC presented here shows that the skewness is not equal to zero and the kurtosis is not equal to three, and thus it is necessary to respect these parameters during the statistical evaluation of the design values, see Table 5. One approach is the application of the Hermite pdf (Kala 2016a), which effectively takes into account small values of skewness and kurtosis and works well for values of kurtosis that are greater than three, however certain combinations of skewness and kurtosis may be inadmissible for values of kurtosis much less than three, see case IV in the last column of Table 5.

Table 6. 0.1 percentiles of LCC (design values)

\begin{tabular}{lccc}
\hline $\begin{array}{c}\text { Cross- } \\
\text { section }\end{array}$ & $\begin{array}{c}\text { Gauss pdf } \\
{[\mathrm{kN}]}\end{array}$ & $\begin{array}{c}\text { Lognormal } \\
\text { pdf } \\
{[\mathrm{kN}]}\end{array}$ & $\begin{array}{c}\text { Hermite pdf } \\
{[\mathrm{kN}]}\end{array}$ \\
\hline Hollow & $249.74^{\mathrm{abc}}$ & $257.39^{\mathrm{abc}}$ & $246.24^{\mathrm{abc}}$ \\
Open & $219.19^{\mathrm{ac}}$ & $223.53^{\mathrm{ac}}$ & $203.92^{\mathrm{c}}$ \\
\hline
\end{tabular}

Table 6 contains a generalization of the design values for the category of open cross-section, which was obtained (similarly as in Table 4) by merging categories II to $\mathrm{V}$ into a set and evaluating the 0.1 percentile from the set of 248 realizations of LCC. Design LCC of the column with hollow cross-section is 14 to 20 percent greater than in the case of the column with open cross-section, see Table 6 .

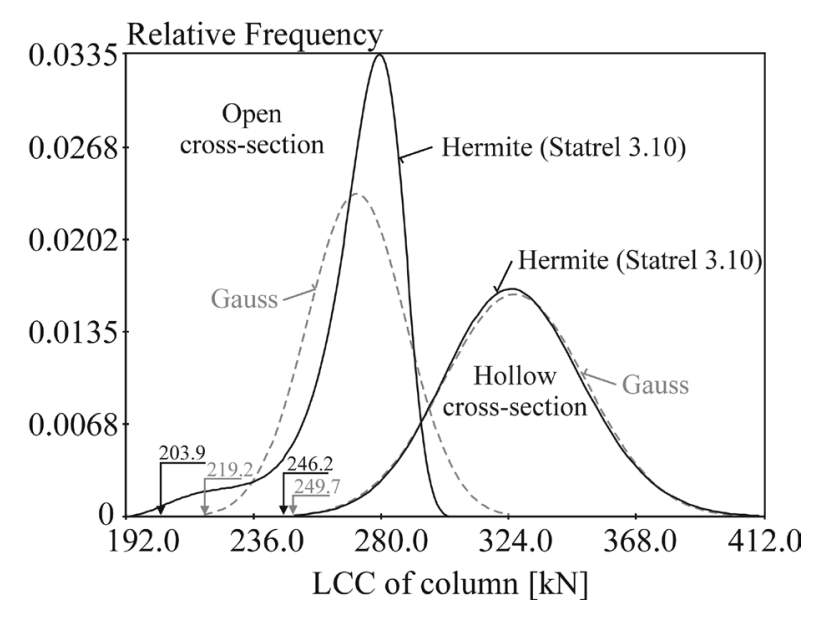

Fig. 10. LCC of columns with open and hollow cross-sections

\section{Conclusions}

LCC of a steel column under compression with spatial axial curvature may be significantly influenced by torsion, which is transferred more effectively in hollow cross-sections than in open cross-sections. The torsional performance of the cross-section of such a column may be as important as the performance under compression or bending, which is shown in the entire spectrum of random realizations of initial axial curvatures. The initial spatial axial curvature due to random fields has a large influence on the statistical variance of the results.

LCC of columns with (i) open square cross-section is approximately $15 \%$ lower than LCC of the same columns with (ii) hollow cross-section, which applies to both the mean and design values. Between cases (i) and (ii) are large differences in the obtained values of skewness and kurtosis of LCC. LCC of columns (i) has skewness of -0.4 and kurtosis 2.5 in contrast to (ii), where the skewness is 0.1 and kurtosis is 3.2 . The correlation 
is approximately 0.72 between the LCC of columns with (i) and (ii). A very strong correlation exists between LCC of columns (i) whose cross-sections have incisions on the opposite side. Lower values of the LCC of columns (i) are accompanied by a different distribution of von Misses stress, which includes lower stress from axial compression (due to lower LCC), a different bending stress distribution (due to higher deformations and different positions of the cross-section upon reaching yield strength) and especially higher and differently distributed stress due to torsion. On the contrary, columns (ii) exhibit higher values of LCC due to higher stiffness of the cross-section in torsion and lower more favourably distributed stress in torsion.

Large differences in the behaviours of columns with (i) open and (ii) hollow cross-sections are also evident from the buckling trajectory of the sixth node in the midlength of the column. The increasing compression load moves the node (i) along the curve or (ii) along the line segment, see Fig. 8. It holds for the results that the difference between realizations of columns (i) and (ii) is only in the torsional stiffness due to the varying warping section constant $I_{\omega}$ and torsion constant $I_{t}$, see Table 1 . Movement along the straight section implies that the section (ii) has high torsional stiffness. On the contrary, movement along the curve implies that the cross-section (i) has low torsional stiffness. Deformation (i) is up to twice higher than deformation (ii) upon reaching LCC. Columns whose cross-sections have incisions on opposite sides have similar deformation curves.

The above described effects of torsion on LCC are caused by the spatial axial curvature and are observed in cross-sections with the same principal second moments of area. Consequently, the sensitivity of the LCC to phenomena associated with torsion of cross-sections in compression is high, because buckling is not predetermined in the direction of major axis bending. The question is whether and to what extent the conclusions presented here can be generalized for columns in compression with open cross-sections whose principal second moments of area are different.

\section{Acknowledgements}

This result was achieved with the financial support of the projects GAČR 17-01589S and LO1408 “AdMAs UP”.

\section{References}

Ádány, S. 2014. Flexural buckling of simply-supported thinwalled columns with consideration of membrane shear deformations: Analytical solutions based on shell model, Thin-Walled Structures 74: 36-48. https://doi.org/10.1016/j.tws.2013.09.014

Adler, R. J.; Taylor, J. E. 2007. Random fields and geometry. $1^{\text {th }}$ edition. Springer. $454 \mathrm{p}$.

Agüero, A; Pallarés, F. J. 2007. Proposal to evaluate the ultimate limit state of slender structures. Part 1: Technical aspects, Engineering Structures 29(4): 483-497. https://doi.org/10.1016/j.engstruct.2006.05.014
Anderson, T. W.; Darling, D. A. 1952. Asymptotic theory of certain "goodness-of-fit" criteria based on stochastic processes, Annals of Mathematical Statistics 23(2): 193-212. https://doi.org/10.1214/aoms/1177729437

Anderson, T. W.; Darling, D. A. 1954. A test of goodness-offit, Journal of the American Statistical Association 49: 765-769.

https://doi.org/10.1080/01621459.1954.10501232

ANSYS. 2014. ANSYS theory release 15.1.

Argyris, J.; Kačianauskas, R. 1996. Semi-analytical finite elements in the higher-order theory of beams, Computer Methods in Applied Mechanics and Engineering 138(1-4): 19-72. https://doi.org/10.1016/0045-7825(95)00975-2

Bucher, C. 2006. Applications of random field models in stochastic structural mechanics, Solid Mechanics and its Applications 140(1): 471-484. https://doi.org/10.1007/1-4020-4891-2 39

Chen, G.; Zhang, H.; Rasmussen, K. J. R.; Fan, F. 2016. Modeling geometric imperfections for reticulated shell structures using random field theory, Engineering Structures 126: 481-489. https://doi.org/10.1016/j.engstruct.2016.08.008

EN 1993-1:2005. Eurocode 3: Design of steel structures Part 1: General rules and rules for buildings.

EN 1990 Eurocode. Basis of structural design, 2003.

Fatmi, R. E. 2007. Non-uniform warping including the effects of torsion and shear forces. Part I: A general beam theory, International Journal of Solids and Structures 44(18-19): 5912-5929. https://doi.org/10.1016/j.ijsolstr.2007.02.006

Galambos, T. V. 1998. Guide to stability design criteria for metal structures. $5^{\text {th }}$ edition. Wiley. $911 \mathrm{p}$.

Groh, R. M. J.; Weaver, P. M. 2015. Static inconsistencies in certain axiomatic higher-order shear deformation theories for beams, plates and shells, Composite Structures 120(1): 231-245.

https://doi.org/10.1016/j.compstruct.2014.10.006

Huntington, D. E.; Lyrintzis, C. S. 1998. Improvements to and limitations of latin hypercube sampling, Probabilistic Engineering Mechanics 13(4): 245-253. https://doi.org/10.1016/S0266-8920(97)00013-1

Iman, R. L.; Conover, W. J. 1980. Small sample sensitivity analysis techniques for computer models. With an application to risk assessment, Communications in Statistics - Theory and Methods 9(17): 1749-1842. https://doi.org/10.1080/03610928008827996

Jönsson, J.; Stand, T. C. 2017. European column buckling curves and finite element modelling including high strength steels, Journal of Constructional Steel Research 128: 136-151. https://doi.org/10.1016/j.jcsr.2016.08.013

Kala, Z. 2007. Stability problems of steel structures in the presence of stochastic and fuzzy uncertainty, Thin-Walled Structures 45: 10-11. https://doi.org/10.1016/j.tws.2007.08.007

Kala, Z. 2009. Sensitivity assessment of steel members under compression, Engineering Structures 31(6): 1344-1348. https://doi.org/10.1016/j.engstruct.2008.04.001

Kala, Z. 2011. Sensitivity analysis of steel plane frames with initial imperfections, Engineering Structures 33: 2342-2349. https://doi.org/10.1016/j.engstruct.2011.04.007

Kala, Z. 2012. Geometrically non-linear finite element reliability analysis of steel plane frames with initial imperfections, Journal of Civil Engineering and Management 18(1): 81-90. https://doi.org/10.3846/13923730.2012.655306

Kala, Z. 2015. Reliability analysis of the lateral torsional buckling resistance and the ultimate limit state of steel beams with random imperfections, Journal of Civil Engineering and Management 21(7): 902-911. https://doi.org/10.3846/13923730.2014.971130 
Kala, Z. 2016a. Global interval sensitivity analysis of Hermite probability density function percentiles, International Journal of Mathematical Models and Methods in Applied Sciences 10: 373-380.

Kala, Z. 2016b. Global sensitivity analysis in stability problems of steel frame structures, Journal of Civil Engineering and Management 22(3): 417-424.

https://doi.org/10.3846/13923730.2015.1073618

Kala, Z.; Kala, J. 2011. Sensitivity analysis of stability problems of steel structures using shell finite elements and nonlinear computation methods, in Proc. of the $9^{\text {th }}$ International Conference "Numerical Analysis and Applied Mathematics (ICNAAM)", 19-25 September 2011, Halkidiki, Greece. American Institute of Physics: AIP Conference Proceedings 1389: 1865-1868.

https://doi.org/10.1063/1.3636974

Kala, Z.; Valeš, J. 2017. Global sensitivity analysis of lateraltorsional buckling resistance based on finite element simulations, Engineering Structures 134: 37-47. https://doi.org/10.1016/j.engstruct.2016.12.032

Kala, Z.; Melcher, J.; Puklický, L. 2009. Material and geometrical characteristics of structural steels based on statistical analysis of metallurgical products, Journal of Civil Engineering and Management 15(3): 299-307. https://doi.org/10.3846/1392-3730.2009.15.299-307

Kala, Z.; Kala, J.; Omishore, A. 2016. Probabilistic buckling analysis of thin-walled steel columns using shell finite elements, International Journal of Mechanics 10: 213-218.

Kamiński, M.; Świta, P. 2015. Structural stability and reliability of the underground steel tanks with the stochastic finite element method, Archives of Civil and Mechanical Engineering 15(2): 593-602. https://doi.org/10.1016/j.acme.2014.04.010

King, C. M.; Davison, J. B. 2017. Development of a proposed design method for discontinuous columns in braced frames, Journal of Constructional Steel Research 128: 233-244. https://doi.org/10.1016/j.jcsr.2016.08.017

Králik, J. 2009. Reliability analysis of structures using stochastic finite element method. STU Bratislava. $143 \mathrm{p}$.

Levinson, M. 1981. A new rectangular beam theory, Journal of Sound and Vibration 74(1): 81-87.

https://doi.org/10.1016/0022-460X(81)90493-4

Massey, F. J. 1951. The Kolmogorov-Smirnov test for goodness of fit, Journal of the American Statistical Association 46: 68-78. https://doi.org/10.1080/01621459.1951.10500769

Matthies, H. G.; Brenner, C. E.; Bucher, C. G.; Soares, C. G. 1997. Uncertainties in probabilistic numerical analysis of structures and solids - stochastic finite elements, Structural Safety 19(3): 283-336. https://doi.org/10.1016/S0167-4730(97)00013-1

Matthies, H.G.; Bucher, C. G. 1999. Finite elements for stochastic media problems, Computer Methods in Applied Mechanics and Engineering 168(1-4): 3-17. https://doi.org/10.1016/S0045-7825(98)00100-5

McKey, M. D.; Conover, W. J.; Beckman, R. J. 1979. A comparison of the three methods of selecting values of input variables in the analysis of output from a computer code, Technometrics 21(2): 239-245. https://doi.org/10.2307/1268522

Melcher, J.; Kala, Z.; Holický, M.; Fajkus, M.; Rozlívka, L. 2004. Design characteristics of structural steels based on statistical analysis of metallurgical products, Journal of Constructional Steel Research 60(3-5): 795-808. https://doi.org/10.1016/S0143-974X(03)00144-5

Mindlin, R. 1951. Influence of rotary inertia and shear on flexural motion of isotropic elastic plates, Journal of Applied Mechanics 18(1): 31-38.
Mokos, V. G.; Sapountzakis, E. J. 2011. Secondary torsional moment deformation effect by BEM, International Journal of Mechanical Sciences 53: 897-909.

https://doi.org/10.1016/j.ijmecsci.2011.08.001

Murín, J.; Kutiš, V. 2008. An effective finite element for torsion of constant cross-sections including warping with secondary torsion moment deformation effect, Engineering Structures 30(10): 2716-2723.

https://doi.org/10.1016/j.engstruct.2008.03.004

Murín, J.; Aminbaghai, M.; Kutíš, V.; Královič, V., Sedlár, T.; Goga, V.; Mang, H. A. 2014. A New 3D Timoshenko finite beam element including non-uniform torsion of open and closed cross sections, Engineering Structures 59: 153-160. https://doi.org/10.1016/j.engstruct.2013.10.036

Murín, J.; Goga, V.; Aminbaghai, M.; Hrabovsky, J.; Sedlár, T.; Mang, H. A. 2017. Measurement and modelling of torsional warping free vibrations of beams with rectangular hollow cross-sections, Engineering Structures 136: 68-76. https://doi.org/10.1016/j.engstruct.2016.12.037

Pasternak, H.; Kubieniec, G. 2016. Implementation of longitudinal welding stresses into structural calculation of steel structures, Journal of Civil Engineering and Management 22(1): 47-55.

https://doi.org/10.3846/13923730.2014.994029

Pearson, K. 1900. On the criterion that a given system of deviations from the probable in the case of a correlated system of variables is such that it can be reasonably supposed to have arisen from random sampling, Philosophical Magazine 50(302): 157-175. https://doi.org/10.1080/14786440009463897

Rondal, J.; Würker, K. G.; Dutta, D.; Wardenier, J.; Yeomans N. 1992. Structural stability of hollow sections. $1^{\text {st }}$ edition. TÜV Verlag. $57 \mathrm{p}$.

Rubin, H. 2006. Torsions-Querschnittswerte für rechteckige Hohlprofile nach EN 10210-2 [Torsional cross-sectional values for rectangular hollow cross-sections, according to EN 10210-2], Stahlbau 76(1): 21-33. https://doi.org/10.1002/stab.200710004

Shayan, S.; Rasmussen, K. J. R.; Zhang, H. 2014. On the modelling of initial geometric imperfections of steel frames in advanced analysis, Journal of Constructional Steel Research 98: 167-177. https://doi.org/10.1016/j.jcsr.2014.02.016

Sedlacek, G.; Müller, C. 2006. The European standard family and its basis, Journal of Constructional Steel Research 62(11): 1047-1059.

https://doi.org/10.1016/j.jcsr.2006.06.027

Sedlacek, G.; Kraus, O. 2007. Use of safety factors for the design of steel structures according to the Eurocodes, Engineering Failure Analysis 14(3): 434-441. https://doi.org/10.1016/j.engfailanal.2005.08.002

Senjanović, I; Vladimir, N.; Hadžić, N.; Tomić, M. 2016. New first order shear deformation beam theory with in-plane shear influence, Engineering Structures 110: 169-183. https://doi.org/10.1016/j.engstruct.2015.11.032

Thai H. T.; Uy B.; Kang W. H.; Hicks S. 2016. System reliability evaluation of steel frames with semi-rigid connections, Journal of Constructional Steel Research 121: 29-39. https://doi.org/10.1016/j.jcsr.2016.01.009

Timoshenko, S. P. 1934. Theory of elasticity. $1^{\text {st }}$ ed. McGraw Hill. 416 p.

Timoshenko, S. P.; Gere, J. M. 1936. Theory of elastic stability. $1^{\text {st }}$ ed. McGraw Hill. 518 p.

Trahair, N. S. 1977. The behaviour and design of steel structures. $2^{\text {nd }}$ ed. Wiley. $320 \mathrm{p}$.

Vainiūnas, P.; Šalna, R.; Šakinis, D. 2015. Probability based design of punching shear resistance of column to slab connections, Journal of Civil Engineering and Management 21(6): 804-812. https://doi.org/10.3846/13923730.2015.1043339 
Valeš, J. 2013. Effect of random axial curvature on the performance of open and closed section steel columns, in Proc. of the $11^{\text {th }}$ International Conference "Numerical Analysis and Applied Mathematics (ICNAAM)”, 21-27 September 2013, Rhodes, Greece. American Institute of Physics: AIP Conference Proceedings 1558: 2512-2515.

Vanmarcke, E. H. 1983. Random fields: analysis and synthesis. $2^{\text {nd }}$ ed. MIT Press. 364 p. https://doi.org/10.1142/5807

Vanmarcke, E. 2010. Random fields: analysis and synthesis. $5^{\text {th }}$ ed. World Scientific. 350 p.

Vlasov, V. Z. 1959. Thin-walled elastic bars. $2^{\text {nd }}$ ed. Fizmatgiz. $493 \mathrm{p}$.

Vořechovský, M.; Novák, D. 2009. Correlation control in smallsample Monte Carlo type simulations I: A simulated annealing approach, Probabilistic Engineering Mechanics 24(3): 452-462. https://doi.org/10.1016/j.probengmech.2009.01.004

Vryzidis, I.; Stefanou, G.; Papadopoulos, V. 2013. Stochastic stability analysis of steel tubes with random initial im- perfections, Finite Elements in Analysis and Design 77: 31-39. https://doi.org/10.1016/j.finel.2013.09.002

Wardenier, J. 2002. Hollow sections in structural applications. $1^{\text {st }}$ ed. CIDECT. $232 \mathrm{p}$.

Xi, Z.; Youn, B. D.; Jung, B. C.; Yoon, J. T. 2015. Random field modeling with insufficient field data for probability analysis and design, Structural and Multidisciplinary Optimization 51(3): 599-611. https://doi.org/10.1007/s00158-014-1165-0

Yang, P. C., Norris, C. H., Stavsky, Y. 1966. Elastic wave propagation in heterogeneous plates, International Journal of Solids and Structures 2(4): 665-684. https://doi.org/10.1016/0020-7683(66)90045-X

Zhang, H.; Shayan, S.; Rasmussen, K. J. R.; Ellingwood, B. R. 2016. System-based design of planar steel frames, I: Reliability framework, Journal of Constructional Steel Research 123: 135-143.

https://doi.org/10.1016/j.jcsr.2016.05.004

Zdeněk KALA. Professor, PhD, Department of Structural Mechanics, Brno University of Technology, Faculty of Civil Engineering. Co-author of 14 books, 3 textbooks and more than 180 scientific papers (120 published abroad). Research interests: elastic-plastic analysis, stability problems, sensitivity analysis and optimization of steel and steel-concrete structures including material and geometrical non-linearities, numerical methods in structural mechanics, and reliability methods.

Jan VALEŠ. PhD student, Department of Structural Mechanics, Brno University of Technology, Faculty of Civil Engineering. Research interests: stability problems, sensitivity analysis.

Jeppe JÖNSSON. Professor, PhD MSc Struct. Eng., Department of Civil Engineering, Technical University of Denmark. Research interests: steel structures, advanced steel structures, thin-walled structures, stability problems, buckling, European column buckling curves, glass and glass structures. 